\title{
Cistitis hemorrágica relacionada al trasplante de médula ósea: Primer reporte de casos en el país
}

\author{
JUAN NUNURA ${ }^{1}$, JUAN NAVARRO ${ }^{2}$ \\ ${ }^{1}$ Residente de II año en la especialidad de Medicina de Enfermedades infecciosas y tropicales. UNMSM. \\ Centro Médico Naval. ${ }^{2}$ Médico Jefe de la Unidad de Trasplante de Médula Osea del Hospital. \\ Nacional Edgardo Rebagliati Martins. ESSALUD. Lima Perú.
}

\begin{abstract}
Resumen
Objetivo: Determinar la incidencia, características clínicas y complicaciones de la cistitis hemorrágica $(\mathrm{CH})$. Material y Métodos: Estudio descriptivo sobre pacientes transplantados de médula ósea en la Unidad de Trasplante de Médula Ósea del Hospital Nacional Edgardo Rebagliati Martins, desde noviembre 1994 hasta octubre 2003, y que desarrollaron cistitis hemorrágica. Resultados: En 9 años fueron transplantados 170 pacientes, desarrollando cistitis hemorrágica 8 de ellos (incidencia acumulada 4,7\%). El cuadro clínico se caracterizó por disuria más hematuria macroscópica o microscópica. La presentación tardía fue la más frecuente. En 4 pacientes, la cistitis hemorrágica fue severa. Dos de los tres pacientes que desarrollaron el cuadro de cistitis hemorrágica en dos oportunidades, fallecieron. Conclusiones: La mitad de los pocos pacientes que desarrollan $\mathrm{CH}$ en la Unidad, lo hacen bajo la forma severa y, si presentan la $\mathrm{CH}$ por segunda vez, su pronóstico se complica.
\end{abstract}

Palabras clave: Cistitis; trasplante de médula ósea; purgación de la médula ósea.

\begin{abstract}
Hemorrhagic cystitis in bone marrow transplant recipients: First report of cases in our country

\section{Abstract}

Objective: To determine the incidence, clinical features and complications of bone marrow transplant-related hemorrhagic cystitis (HC). Material and Methods: Retrospective study of bone marrow transplant patients attended at the Edgardo Rebagliati Martins National Hospital Bone Marrow Transplant Unit from November 1994 to October 2003 and who developed HC. Results: A total of 170 patients underwent hematopoietic cell transplantation. Eight patients developed HC with a cumulative incidence of $4,7 \%$, characterized by mainly late onset hematuria and dysuria. In 4 patients, the $\mathrm{HC}$ was severe. Two of the three patients who developed HC twice died. Conclusions: Half of the few patients with HC attended at the Unit developed serious disease and when they had HC for a second time the prognosis was fatal.
\end{abstract}

Key words: Cystitis; bone marrow transplantation; bone narrow purging.

\footnotetext{
Correspondencia:

Dr. Juan Manuel Nunura Reyes

Jirón Las Mercedes 231, Cercado de Lima

Lima 01, Perú

E-mail: jmnunura@yahoo.es
} 


\section{INTRODUCCIÓN}

La etiología de la cistitis hemorrágica $(\mathrm{CH})$ es variada. Si se presenta durante o posterior al condicionamiento, se la considera como de inicio temprano y está más frecuentemente asociada con el uso de ciclofosfamida, busulfan $\left({ }^{1}\right)$; mientras que las de presentación tardía están asociadas con infecciones, principalmente las producidas por adenovirus $\left({ }^{2}\right)$. No se ha determinado aún, si se trata de una manifestación de la enfermedad injerto contra huésped (EICH) $\left(^{3}\right)$.

Clínicamente, la $\mathrm{CH}$ puede ser desde leve a severa. La CH de tipo severa trae una serie de complicaciones que requieren una prolongada y costosa hospitalización $\left({ }^{4}\right)$.

Mientras que se ha obtenido mucho éxito en la prevención de la $\mathrm{CH}$ de presentación temprana con la hiperhidratación y el uso de MESNA (2Mercaptoetano-Sulfonato sódico) $\left({ }^{5}\right)$, en las de inicio tardío, el tratamiento es generalmente paliativo y de soporte, lo cual puede resultar insuficiente cuando se presentan complicaciones que pueden amenazar la vida del paciente $\left({ }^{6}\right)$.

\section{MATERIAL Y MÉTODOS}

Se estudió todos los pacientes transplantados de médula ósea en el Hospital Nacional Edgardo Rebagliati Martins (HERM), desde el inicio de los trasplantes en noviembre 1994 hasta octubre 2003. La información se obtuvo de la base de datos de la Unidad. Un total de 170 pacientes fueron transplantados, seis de ellos en 2 oportunidades.

Se usó los siguientes regímenes de condicionamiento:

ВиCy: busulfan $4 \mathrm{mg} / \mathrm{kg} /$ día por 4 días y ciclofosfamida $60 \mathrm{mg} / \mathrm{kg} /$ día por 2 días) para leucemia mieloide.

Cy-GAL: ciclofosfamida $200 \mathrm{mg} / \mathrm{kg}$ dosis total y globulina antilinfocitaria $30 \mathrm{mg} / \mathrm{kg} / \mathrm{día}$ por 3 días para anemia aplásica.
Cy-TBI: ciclofosfamida $60 \mathrm{mg} / \mathrm{kg} /$ día por 2 días y TBI standard 1200) para síndrome mielodisplásico.

Cy-TBI-ETO: ciclofosfamida $8,4 \mathrm{~g}$ dosis total + TBI standard + etopósido $2,8 \mathrm{~g}$ dosis total para leucemia linfocítica aguda.

Todos los pacientes a quienes se indicó Cy como parte del régimen de condicionamiento, recibieron hiperhidratación ( $3 \mathrm{~L} / \mathrm{m}^{2} /$ día) y MESNA a $100-120 \%$ de la dosis de Cy. Todos los productos sanguíneos fueron leucocitos depletados por filtración e irradiación previo a la transfusión. Todos los pacientes recibieron ciclosporina y metotrexate para la profilaxis de enfermedad injerto contra huésped.

En aquellos pacientes de riesgo para enfermedad veno oclusiva hepática, se indicó $100 \mathrm{UI} / \mathrm{kg}$ de heparina en infusión continua en 24 horas. El factor estimulante de colonias granulocíticas fue dado desde el día +6 .

Se ha definido la cistitis hemorrágica como un síndrome caracterizado por hematuria de por lo menos 5 días de duración (macroscópica o microscópica) y síntomas de cistitis (disuria, polaquiuria, etc.) durante o posterior al condicionamiento.

Según la severidad de la hematuria, se clasificó a la $\mathrm{CH}$ en: a) Grado 1, hematuria microscópica; b) Grado 2, hematuria macroscópica sin expulsión de coágulos; c) Grado 3, hematuria macroscópica con expulsión de coágulos sin obstrucción; y, d) Grado 4, hematuria macroscópica con coágulos en la ecografía que pueden o causan retención urinaria.

Clínicamente, se puede categorizar a la $\mathrm{CH}$ en: a) Leve, corresponde al grado 1 de hematuria; b) Moderada, corresponde a los grados 2 y 3 de hematuria; y, c) Severa, corresponde al grado 4, cuando se requiere instrumentación para el lavado de los coágulos y/o irrigación continua.

La CH fue clasificada como de presentación temprana cuando ocurría hasta los 21 días 
postrasplante y como de presentación tardía, cuando era posterior a los 21 días .

Todos los resultados de cultivos para virus o exámenes de inmunofluorescencia indirecta (IFI) fueron realizados en el Instituto Nacional de Salud por indicación del médico tratante y los gastos fueron cubiertos por los pacientes.

\section{RESULTADOS}

Un total de 170 pacientes, 93 del sexo masculino y 77 del femenino, fueron transplantados en la Unidad de Trasplante de Médula Ósea del HNERM, seis de ellos en dos oportunidades; 128 fueron trasplante alogénico, 38 autólogo y 4 singénico. El promedio de edad de los pacientes fue 28,56 años (rango de 2 a 64 años).

La indicación para trasplante fue anemia aplásica en 36, leucemia mieloide crónica (LMC) en 32, leucemia linfoblástica aguda (LLA) en 32, leucemia mieloide aguda (LMA) en 23, mieloma múltiple (MM) en 13, linfoma no Hodgkin (LNH) en 11, linfoma Hodgkin (LH) en 8 y otras en 15 pacientes (Tabla 1).

En la Unidad de Trasplante de Médula Ósea del Hospital, sólo se transplanta alogénicos compatibles relacionados. De los trasplantes alogénicos, el stem cell fue de médula ósea en 62 pacientes, en 60 fue de sangre periférica y en 6 el trasplante fue mixto.

Del total de pacientes transplantados, ocho (tres de ellos en dos oportunidades) desarrollaron $\mathrm{CH}$ (incidencia acumulada de 4,7\%). El tiempo promedio de presentación del cuadro fue a los 129,4 días, rango -4 a +294 . Hubo 2 casos de $\mathrm{CH}$ de inicio temprano y 9 de presentación tardía.

El promedio de duración de la $\mathrm{CH}$ fue de 35,6 días, rango de 6 a 104 días. Las $\mathrm{CH}$ de inicio temprano tuvieron un tiempo promedio de duración de 66 días; en cambio, las $\mathrm{CH}$ de inicio tardío tuvieron un tiempo promedio de duración de 28,9 días.
Según la hematuria, 2 casos $(18,2 \%)$ fueron de grado $1,1(9,1 \%)$ de grado $2,3(27,3 \%)$ de grado 3 y $5(45,5 \%)$ de grado 4 . La $\mathrm{CH}$ fue severa en 5 casos y una paciente hizo $\mathrm{CH}$ severa en dos oportunidades.

Los síntomas y signos de la $\mathrm{CH}$ (Tabla 2) fueron hematuria (macro o microscópica) en todos los 8 pacientes (tres pacientes hicieron el cuadro de $\mathrm{CH}$ en dos oportunidades), disuria en $8 / 11$ casos (en 4 de ellos la disuria fue terminal), polaquiuria en $4 / 11$ casos, tenesmo en $3 / 11$, obstrucción urinaria en 3/11 casos, dolor lumbar y/o puño percusión lumbar positivo en $3 / 11$ casos. En dos de estos tres últimos pacientes, se encontró malformaciones urinarias en la urografía excretoria. El tercer paciente con dolor

Tabla 1.- Características de los pacientes transplantados.

\begin{tabular}{lcc}
\hline Variables & CH & no CH \\
\hline Número de pacientes & 8 & 162 \\
Promedio de edad (años) & 27 & 29 \\
Masculino / femenino & $7 / 1$ & $86 / 76$ \\
Enfermedad subyacente & & \\
$\quad$ Leucemia mieloide crónica & 3 & 29 \\
$\quad$ Leucemia mieloide aguda & 2 & 21 \\
$\quad$ Leucemia linfoblástica aguda & 1 & 31 \\
$\quad$ Anemia aplásica & 1 & 35 \\
$\quad$ Síndrome mielodisplásico & 1 & 2 \\
Régimen de condicionamiento & & \\
$\quad$ Contiene Ciclofosfamida & 8 & 128 \\
$\quad$ Contiene Busulfán & 5 & 48 \\
$\quad$ Contiene TBI (Irradiación & & \\
$\quad$ corporal total) & 2 & 42 \\
Tipo de transplante de Médula ósea & & \\
$\quad$ Autólogo & 0 & 38 \\
$\quad$ Singénico & 0 & 4 \\
$\quad$ Alogénico & & \\
$\quad$ relacionado compatible & 8 & 120 \\
$\quad$ no relacionado & 0 & 0 \\
Enfermedad injerto contra huésped agudo & \\
$\quad$ < 2 & 0 & 12 \\
E2 & 3 & 17 \\
$\quad$ Extermedad injerto contra huésped crónico & 3 & \\
Localizado & 0 & 5 \\
\hline
\end{tabular}


Tabla 2.- Características clínicas de los pacientes con cistitis hemorrágica.

\begin{tabular}{|c|c|c|c|c|c|c|c|c|c|c|}
\hline $\mathrm{n}$ & Edad & Sexo & Enferm. & $\begin{array}{c}\text { Fecha } \\
\text { TMO }\end{array}$ & $\begin{array}{c}\text { Día inicio } \\
\text { CC }\end{array}$ & $\begin{array}{l}\text { Cuadro } \\
\text { clínico* }\end{array}$ & $\begin{array}{c}\text { Duración } \\
\text { de } \mathrm{CH}\end{array}$ & $\begin{array}{l}\text { Grado } \\
\text { de } \mathrm{CH}\end{array}$ & $\mathrm{EICH}$ & Obs \\
\hline 1 & 20 & M & $\begin{array}{l}\text { LMA } \\
\text { recaída }\end{array}$ & 28/09/96 & $\begin{array}{c}-2 \\
+276\end{array}$ & $\begin{array}{c}\text { d,c, a,b } \\
\text { a,c,e,f }\end{array}$ & $\begin{array}{c}104 \mathrm{~d} \\
32 \mathrm{~d}\end{array}$ & $\begin{array}{l}\text { III } \\
\text { IV }\end{array}$ & $\begin{array}{l}(-) \\
(-)\end{array}$ & $\begin{array}{c}\text { Falleció } \\
+307\end{array}$ \\
\hline 2 & 38 & M & LMC & $28 / 10 / 98$ & +294 & $\mathrm{a}, \mathrm{c}, \mathrm{b}, \mathrm{e}$ & $21 \mathrm{~d}$ & III & cron & \\
\hline 3 & 19 & M & LMA & $30 / 10 / 99$ & +278 & $\mathrm{~b}, \mathrm{a}, \mathrm{g}$ & $16 \mathrm{~d}$ & II & cron & \\
\hline 4 & 16 & M & AA & $31 / 05 / 00$ & +25 & $\mathrm{~b}, \mathrm{a}$ & $6 \mathrm{~d}$ & $\mathrm{I}$ & ag & \\
\hline 5 & 25 & $\mathrm{~F}$ & MDS & 05/06/01 & $\begin{array}{c}+22 \\
+147\end{array}$ & $\begin{array}{c}\mathrm{b}, \mathrm{d}, \mathrm{a} \\
\mathrm{a}, \mathrm{f}\end{array}$ & $\begin{array}{l}58 \mathrm{~d} \\
25 \mathrm{~d}\end{array}$ & $\begin{array}{l}\text { IV } \\
\text { IV }\end{array}$ & $\begin{array}{l}\text { ag } \\
\text { cron }\end{array}$ & \\
\hline 6 & 38 & M & $\begin{array}{l}\mathrm{LMC} \\
\text { recaída }\end{array}$ & 16/17 Julio 01 & $\begin{array}{c}-4 \\
+86\end{array}$ & $\frac{\mathrm{a}}{\mathrm{a}, \mathrm{b}, \mathrm{c}, \mathrm{d}}$ & $\begin{array}{l}28 \mathrm{~d} \\
24 \mathrm{~d}\end{array}$ & $\begin{array}{c}\text { I } \\
\text { III }\end{array}$ & $\begin{array}{l}(-) \\
(-)\end{array}$ & $\begin{array}{c}\text { Falleció } \\
+109\end{array}$ \\
\hline 7 & 39 & M & LMC & $07 / 02 / 02$ & +56 & $\mathrm{~b}, \mathrm{a}$ & $35 \mathrm{~d}$ & IV & $\mathrm{ag}$ & \\
\hline 8 & 21 & M & LLA & $10 / 01 / 03$ & +245 & $b, e, a, f$ & $43 \mathrm{~d}$ & IV & cron & \\
\hline
\end{tabular}

* $a=$ hematuria $e=$ dolor lumbar y/o PPL (+)

$c=$ polaquiuria $g=$ fiebre

lumbar tenía urolitiasis. En 5 oportunidades (5/ 11) se tuvo que cateterizar para lavado vesical y/o irrigación continua.

Con respecto a la evolución de los pacientes con cistitis hemorrágica, el primer paciente POU inició el cuadro el día -2 , prendió en el día +12 ; en el día +22 se inició ganciclovir. La hematuria recrudeció estando hospitalizado, en el día +30 , aparentemente al "disminuir la dosis de ganciclovir". Fue dado de alta con aparente mejoría y sin hematuria. Sin embargo, en los controles ambulatorios presentaba algunas veces hematuria macroscópica. En el día +75 , la hematuria se hizo franca y nuevamente intermitente, hasta el día +102 . Sus urocultivos fueron repetidamente negativos y en un examen ecográfico los riñones fueron informados como normales. El paciente presentó recaída de la enfermedad. Ingresó el día +263 asintomático, para reinducción. Recibió arabinósido $\mathrm{C}$ y daunorubicina (DNM). El día +276 presentó hematuria discreta, a lo cual se agregó polaquiuria y días después, dolor lumbar.

El día +280 presentó obstrucción urinaria. Se realizó lavado vesical; se dejó irrigación continua.

$$
\begin{aligned}
& b=\text { disuria } f=\text { obstrucción de la vía urinaria } \\
& d=\text { tenesmo }
\end{aligned}
$$

Las ecografías informaron de litiasis renal bilateral. El día +289 presentaba hematuria franca y llegó a obstruirse estando con sonda; paciente somnoliento. El día +291 presentó palidez marcada y valores de creatinina y urea en $3,1 \mathrm{mg} / \mathrm{dL}$ y $120 \mathrm{mg} / \mathrm{dL}$, respectivamente. En el día +295 presentó insuficiencia respiratoria tipo I, que evolucionó rápidamente. Fue transferido a la Unidad de Cuidados Intensivos el mismo día. Mielograma: Médula ósea $30 \%$ blastos. Al día siguiente, ictérico con hipoalbuminemia. Hizo atelectasia; por fibrobroncoscopia se obtuvo muestras para bacterias y hongos que resultaron negativas. En el día +302 presentó sangrado digestivo, continuó con hematuria y tuvo compromiso multiorgánico; el día +306 se evidenció trastorno de la coagulación. Falleció al día siguiente, siendo el diagnóstico de defunción neumonía nosocomial.

El segundo caso que presentó $\mathrm{CH}$ en dos oportunidades fue la única mujer de la serie (paciente 5).

Prende el día +9. El día +14 inició ganciclovir, que recibió por 14 días. El día +16 hizo enfermedad injerto contra huésped (EICH) 
agudo III, el cual se controló rápidamente. Inició cuadro de $\mathrm{CH}$ el día +22 .

El día +23 fue diagnosticada de blefaroconjuntivitis y dacriocistitis de etiología a determinar. Urocultivo del día +27 aisló $E$. coli.

La hematuria se hizo intermitente. El día +47 presentó hematuria franca con coágulos, por lo que se instaló al día siguiente irrigación vesical. En el día +51 presentó pico febril. En el día +53 se realizó cistoscopia. Al día +56 , la hematuria persistía. Al día +72 se volvió a aislar E. coli, también sensible a amikacina. Al día +76 , la hematuria era esporádica. Se retiró la sonda. Fue dada de alta en el día +81 , siendo el día 103 de hospitalización.

En el día +148, ingresó por hematuria macroscópica con eliminación de coágulos de 24 h de evolución más EICH crónico extenso de piel y mucosas controlado. Al día siguiente de su ingreso, presentó obstrucción urinaria; se dejó sonda y 5 días después se realizó cistoscopia. En el día +157 , no se observó actividad de EICH y se empezó a disminuir la dosis de prednisolona. En el día +168 , se aisló $E$. coli sensible a cefuroxima y amikacina. Se retiró irrigación y salió de alta 4 días después. Estuvo 24 días hospitalizada.

El tercer paciente con $\mathrm{CH}$ en dos oportunidades (paciente 6) presentó $\mathrm{CH}$ grado I, que inició durante el condicionamiento y se prolongó hasta el día +23 . El día +25 fue operado de apendicitis aguda. Tres días después fue dado de alta. La segunda vez que presentó $\mathrm{CH}$ fue durante una hospitalización en el día +41 . Había ingresado por sepsis a Gram negativo, punto de partida, infección del catéter venoso central más pérdida del injerto (stem insuficiente y/o secundario a infección). Durante mes y medio evolucionó con aparente mejoría, aunque persistió la pancitopenia. Recibió ganciclovir por antigenemia positiva para citomegalovirus ( PP65). La hiperglicemia fue controlada.

El día +86 presentó hematuria macroscópica más síntomas de cistitis y coágulos pequeños.
Dos días después, se aisló en urocultivo E. coli $>100000$ colonias, multirresistente. Urología evaluó: no tributario de sonda. Evolucionó con esplenomegalia dolorosa, anasarca e incremento de la ictericia. La hematuria fue intermitente. Se recibió resultado de cultivo viral de orofaringe positivo a "virus respiratorio" (Tabla 3).

El día +97 presentó por estudio ecográfico hidronefrosis derecha, bazo de $17 \mathrm{~cm}$ (esplenomegalia severa) y leve hepatomegalia. En el día +98 se le realizó un segundo trasplante alogénico de medula ósea que tuvo como condicionamiento BuCy clásico. El día +105 presentó retención de orina, azoemia. Recibió hemodiálisis de apoyo.

El día +108 presentó insuficiencia respiratoria, falleció al día siguiente, siendo su diagnóstico de defunción falla multiorgánica.

Dos de los 5 pacientes restantes presentaron $\mathrm{CH}$ severa que requirieron irrigación continua y lavado vesical (pacientes 7 y 8). Ambos presentaron esplenomegalia moderada e hidronefrosis en la ecografía. Se les realizó cistoscopia (Tabla 3 ). El paciente 8 , a diferencia del paciente 7, evolucionó con obstrucción urinaria. Ambos tenían EICH grado II-III, que disminuyeron clínicamente durante la hospitalización para reaparecer previo al alta. Parte del tratamiento en el paciente 8 , fue la disminución paulatina de los corticoides; en él se obtuvo por IFI y cultivo viral en orina adenovirus y en el otro paciente por IFI en hisopado faríngeo, se encontró adenovirus.

Un día antes del alta en el paciente 7, se tomó urocultivo, aislándose Enterobacter cloacae.

En el examen de urograma excretor en el paciente 8 , se encontró doble sistema pelvicalicilar y ureteral del lado derecho (Tabla 3).

Dos de los tres pacientes restantes tuvieron $\mathrm{CH}$ catalogada como moderada. El paciente 3 inició cuadro clínico en el día +278. Dos días después se inició ganciclovir, que recibió por 
Tabla 3.- Estudios de imágenes, exámenes para virus y cistoscopia.

\begin{tabular}{|c|c|c|c|c|c|}
\hline $\mathrm{n}$ & Ecografía & Urograma excretor & IFI & Cultivo viral & Cistoscopia \\
\hline \multirow[t]{2}{*}{1} & $\begin{array}{l}\text { Primer episodio } \\
\text { informada como normal }\end{array}$ & NR & NR & NR & NR \\
\hline & $\begin{array}{l}\text { Segundo episodio: } \\
\text { nefrolitiasis bilateral } \\
\text { más hidronefrosis leve }\end{array}$ & NR & NR & NR & $\begin{array}{c}\text { Mucosa vesical } \\
\text { con sangrado en napa. } \\
\text { Edema buloso en fondo } \\
\text { y cuello, coágulos }\end{array}$ \\
\hline 2 & de 1 & $\begin{array}{l}\text { Anomalía congénita } \\
\text { rotación de ambos riñon }\end{array}$ & es & NR & NR \\
\hline 3 & $\begin{array}{l}\text { Leve hidronefrosis } \\
\text { bilateral }\end{array}$ & NR & $\begin{array}{c}\text { En suero(+) } \\
\text { Adenovirus } 1 \mathrm{y} \\
7 \text { virus respiratorios }\end{array}$ & $\begin{array}{c}\text { Hisopado faríngeo(-) } \\
\text { para influenza } \\
\text { y otros }\end{array}$ & NR \\
\hline 4 & No litiasis ni hidronefrosis & NR & NR & NR & NR \\
\hline \multirow[t]{2}{*}{5} & $\begin{array}{l}\text { Primer episodio coágulos } \\
\text { intravesicales,hepatomegalia } \\
\text { leve, leve ectasia de } \\
\text { ambos senos renales }\end{array}$ & NR & NR & NR & $\begin{array}{l}\text { Coágulos, mucosa vesical } \\
\text { congestiva principalmente } \\
\text { en fondo vesical que } \\
\text { sangra fácilmente }\end{array}$ \\
\hline & $\begin{array}{l}\text { Segundo episodio fondo } \\
\text { vesical ocupada por coágulos }\end{array}$ & NR & NR & NR & $\begin{array}{l}\text { Mucosa vesical congestiva } \\
\text { en parche, coágulos }\end{array}$ \\
\hline \multirow[t]{2}{*}{6} & NR & NR & NR & NR & NR \\
\hline & $\begin{array}{l}\text { Segundo episodio hepatomegalia } \\
\text { leve, esplenomegalia severa, } \\
\text { hidronefrosis izquierda }\end{array}$ & NR & $\begin{array}{l}\mathrm{H} \\
\text { el pi } \\
\text { a par }\end{array}$ & $\begin{array}{l}\text { Hisopado orofaríngeo(t } \\
\text { atógeno aislado corresp } \\
\text { aainfluenza VSR o aden }\end{array}$ & $\begin{array}{l}(+) \\
\text { ponde } \\
\text { novirus }\end{array}$ \\
\hline 7 & $\begin{array}{l}\text { Hepatopatía crónica, } \\
\text { esplenomegalia moderada } 140 \times 6\end{array}$ & 64 & $\begin{array}{l}\text { Hisopado nasal (+) } \\
\text { AH3N2 adenovirus }\end{array}$ & c & $\begin{array}{l}\text { Coágulos, mucosa hiperémica, } \\
\text { zonas granulomatosas muy } \\
\text { congestivas en toda la base } \\
\text { y fondo, trígono y meato } \\
\text { urinario sin alteraciones }\end{array}$ \\
\hline \multirow[t]{2}{*}{8} & $\begin{array}{l}\text { Leve hidronefrosis derecha } \\
\text { y esplenomegalia } \\
\text { moderada }\end{array}$ & $\begin{array}{l}\text { Doble sistema } \\
\text { pelvicalicilar y ureteral } \\
\text { por lado derecho con } \\
\text { unión en el tercio distal }\end{array}$ & Orina & Orina & $\begin{array}{l}\text { Presencia de } \\
\text { equímosis y petequias en } \\
\text { fondo vesical y caras } \\
\text { laterales. Trígono OK }\end{array}$ \\
\hline & & & $\begin{array}{l}\text { Influenza y otros vir } \\
\text { espiratorios adenoviru }\end{array}$ & (+)Adenovirus & \\
\hline
\end{tabular}

NR : No realizado

21 días. Se agregó al cuadro clínico fiebre al tercer día de hospitalizado. Los hallazgos tomográficos fueron otomastoiditis crónica y nódulo en ápice pulmonar derecho.

El cultivo viral de hisopado faríngeo fue negativo, mientras que el examen de IFI en suero tuvo como resultado adenovirus 1 y 7. Evolucionó favorablemente y fue dado de alta. Posteriormente, el paciente recae de la enfermedad de fondo y fallece el día +1034 .

El paciente 2 inició el cuadro clínico el día +294. Fue una $\mathrm{CH}$ grado III que no necesitó 
irrigación ni cistoscopia. Tuvo aparente mejoría con el uso de ganciclovir. Desde el día +304 recibió ganciclovir por 14 días. No se hizo estudios para virus. El urograma excretor informó anomalía congénita de rotación de ambos riñones.

El paciente 4 tuvo una $\mathrm{CH}$ leve durante hospitalización con motivo del trasplante. Prende el día +11 . Por cuadro respiratorio, se inicio ganciclovir el día +23 . El día +26 inició cuadro clínico de $\mathrm{CH}$, el cual se resolvió en 6 días. Evolucionó favorablemente.

\section{DISCUSIÓN}

La $\mathrm{CH}$ es una importante complicación del trasplante de médula ósea, con una incidencia que varia de $7 \%$ a $76 \%$. La baja incidencia que reportamos la atribuimos a que en la Unidad sólo se transplanta alogénicos relacionados compatibles, a diferencia de otros centros extranjeros. Tres de los 8 pacientes con $\mathrm{CH}$ tenían como enfermedad más frecuente de fondo Leucemia mieloide crónica, lo cual es similar a otros estudios $\left({ }^{7}\right)$.

El punto de corte para definir una $\mathrm{CH}$ de inicio temprano y tardío varía. Algunos consideran posterior a los 30 días postrasplante para las $\mathrm{CH}$ de presentación tardía. Otros tienen en cuenta el día de prendimiento del injerto. Las $\mathrm{CH}$ de presentación tardía tienen duración prolongada y presentan complicaciones $\left(^{8}\right)$. Obtenemos un resultado opuesto al que se esperaría al comparar las $\mathrm{CH}$ de inicio temprano y tardío, debido a que un paciente con $\mathrm{CH}$ de inicio temprano tuvo una hematuria que a partir del día +42 se hizo intermitente, hasta desaparecer el día +104 . No encontramos una respuesta satisfactoria para este hecho.

Hasta la actualidad no se ha determinado si la $\mathrm{CH}$ es una manifestación de la Enfermedad injerto contra huésped.

Las CH de presentación tardía están cada vez mas asociadas con virus, principalmente los adenovirus, de quienes ya se está entendiendo como interactúan con la célula huésped $\left({ }^{9}\right)$.

Las definiciones de $\mathrm{CH}$ según la hematuria y según el cuadro clínico es la misma en comparación a otros trabajos relacionados. Se reporta la lectura ecográfica como el mejor modo de catalogar una $\mathrm{CH}$ como severa y para decidir una irrigación continua, en caso el paciente esté expulsando coágulos. Además, sirve para evaluar el grosor de la pared vesical $\left({ }^{10}\right)$.

Un estudio $\left({ }^{11}\right)$ encuentra una incidencia de $5 \%$, pero sólo para las $\mathrm{CH}$ severas. La mitad de nuestros casos tuvo esta forma de presentación $(2,34 \%)$.

El dolor lumbar se presentó en pacientes con anomalías congénitas del riñón (2 pacientes ) y en un paciente con nefrolitiasis.

Tres de los 11 casos, presentaron obstrucción de la vía urinaria, la cual ocurrió estando ya el paciente hospitalizado, siendo por lo tanto un hecho prevenible.

Por otro lado, 6 de 8 de los pacientes desarrollaron EICH (Tablas 1 y 2) lo cual es un conocido factor de riesgo para $\mathrm{CH}$ y enfermedad adenoviral diseminada $\left({ }^{12}\right)$.

\section{Análisis de los casos}

En el primer paciente hubo una respuesta favorable inicial de la hematuria que fue atribuida al uso de ganciclovir, aunque este fármaco sólo tiene actividad contra algunos serotipos de adenovirus $\left({ }^{13}\right)$. Al paciente no se le encontró explicación alguna para la hematuria intermitente. El paciente recibió antineoplásicos, los cuales no están relacionados con $\mathrm{CH}$. No se utilizó Bucy ni irradiación corporal total. $\mathrm{La} \mathrm{CH}$ desarrollada, al no haber acroleína o EICH, puede haber estado asociada a un virus. Este paciente fue el primero de la serie en presentar el cuadro de $\mathrm{CH}$ y su complicación aunada a otros problemas asociados, hacen suponer una etiología multifactorial. 
El segundo paciente que falleció, también tuvo $\mathrm{CH}$ en dos oportunidades. Fue operado de apendicitis $($ día +25$)$, lo cual puede ser debido al adenovirus $\left({ }^{14}\right)$. Se conoce de la capacidad de estos virus para permanecer en estado latente en el ser humano $\left({ }^{15}\right)$. Desarrolló $\mathrm{CH}$ en el día +86 , agregándose infección del tracto urinario. Se aisló adenovirus en hisopado faríngeo. Ante la evolución desfavorable, se decidió un segundo trasplante. Recibió condicionamiento con ciclofosfamida, el cual tiene un reconocido metabolito (acroleína) que es tóxico para el epitelio vesical. En animales de experimentación, se ha observado que dosis altas de ciclofosfamida pueden ocasionar hemorragia pulmonar $\left({ }^{16}\right)$. Este caso es posible que haya sido una infección por adenovirus diseminada, lo cual ocurre en el contexto de una profunda inmunodeficiencia $\left({ }^{17}\right)$, como la que tuvo el paciente.

La paciente 5 también desarrolló $\mathrm{CH}$ en dos oportunidades. En la primera oportunidad hubiera sido considerado como de presentación temprana, si se hubiera tomado como punto de corte 30 días. Teóricamente hay una respuesta inmune mejorada después del prendimiento $\mathrm{y}$, como este ocurre generalmente antes de los 21 días, algunos trabajos toman este período como referencia $\left({ }^{3}\right)$; así, hemos preferido adoptar esta clasificación. El problema ocular notorio fue diagnosticado por la especialidad y puede ser atribuido a causas virales $\left({ }^{18}\right)$. La hematuria intermitente puede correlacionarse en este caso con infecciones bacterianas del tracto urinario. La paciente reingresó en el día +148 por $\mathrm{CH}$ y al día siguiente presentó obstrucción de la vía urinaria. Se empezó a disminuir dosis de corticoides, dado que clínicamente la actividad del EICH había disminuido. Se aisló E. coli 4 días antes del alta. La paciente evolucionó favorablemente.

Según estos tres casos analizados, el antecedente de haber tenido $\mathrm{CH}$ durante el condicionamiento o inmediatamente después al trasplante sería un factor a tener en cuenta debido a la posibilidad de volver a desarrollar $\mathrm{CH}$ y hacerlo de una forma severa, con el riesgo que ello implica.
Los pacientes 7 y 8 iniciaron el cuadro en una etapa tardía. Ambos lo hicieron de una forma severa, con esplenomegalia moderada e hidronefrosis en la ecografía. Se observó en ellos que el EICH grado III y II, respectivos, disminuyó clínicamente durante la hospitalización, para reaparecer al alta. Un reciente estudio $\left({ }^{19}\right)$ informa una relación inversa entre las manifestaciones de EICH y la detección del adenovirus en un paciente con $\mathrm{CH}$ severa que falleció. Los expertos ya habían sugerido que la $\mathrm{CH}$ pueda ser producto de una acentuada inmunosupresión, como resultado del tratamiento anti EICH $\left({ }^{20}\right)$. Lo que no se ha comunicado hasta ahora, es la disminución de las manifestaciones clínicas de EICH cutáneo grado II-III, conforme se establecía una fase de estado de una $\mathrm{CH}$ severa de probable etiología viral. En estos dos pacientes se logró aislar adenovirus (Tabla 3 ).

En el paciente 8 y en la paciente 5 se decidió bajar las dosis de corticoides, al haber disminuido la actividad del EICH. Teóricamente, con esta medida como parte de un tratamiento para la $\mathrm{CH}$, se mejora la respuesta inmunitaria mediada por células y se recupera, al menos en parte, la actividad antiviral $\left({ }^{21}\right)$.

Se ha observado, también, que los pacientes que tuvieron más lavados vesicales evolucionaron mejor, independientemente de la irrigación continua (pacientes 5 y 8), aún siendo formas severas de $\mathrm{CH}$.

Los pacientes 2 y 8 fueron los únicos a los cuales se les realizó urografía excretoria, encontrándoseles anomalías congénitas, Queda por investigar si estas anomalías son un factor de riesgo para $\mathrm{CH}$, pues servirían como un foco latente infeccioso, en donde estaría alterada la excreción viral.

Aunque la incidencia de $\mathrm{CH}$ es baja en la Unidad de Trasplante de Médula Ósea del Hospital Nacional Edgardo Rebagliati Martins, la mitad de los pacientes que la desarrollan lo hacen como formas severas de la enfermedad, las cuales conllevan una mayor mortalidad, más aun, si el paciente presenta la $\mathrm{CH}$ por segunda vez. 


\section{Agradecimientos}

Agradecemos a todo el personal de la Unidad de Trasplante de Médula Ósea del HNERM por los cuidados que brindan a tan especiales pacientes.

\section{REFERENCIAS BIBLIOGRÁFICAS}

1. Hirsh HH, Steiger J. Review: Poliomavirus BK. The Lancet Infect Dis 2003;3:619.

2. Akiyama H, Kuroso T, Sakasgita C, Inoue T, Mori S, Ohashi $\mathrm{K}$, et al. Adenovirus is a key pathogen in hemorrhagic cystitis associated with bone marrow transplantation. Clin Infect Dis 2001;32:1325.

3. Gyeong_won L, Je_Hwan L, Seong-Jan Choi, Shin Kim, Miee Seol, Woo-Kun Kim. Hemorrhagic cystitis following allogeneic hematopoietic cell transplantation. J Korean Med Sci 2003;18:194.

4. Yang CC, Hurd DD, Case LD, Assimos DG. Hemorrhagic cystitis in bone marrow transplantation. Urol 1994;44(3):322.

5. Shepherd JD, Pringle LE, Barnett MJ, Klingemann HG, Reece DE, Phillips GL. Mesna versus hyperhydration for the prevention of cyclophosphamide induced hemorrhagic cystitis in bone marrow transplantation. J Clin Oncology 1991;9:2016.

6. Legrand F, Berrebi D, Houhou N, Freymuth F, Faye A, Duval M, et al. Early diagnosis of adenovirus infection and treatment with cidofovir after bone marrow transplantation in children. Bone Marrow Transplant 2001;27:621.

7. Leung AYH, Mak R, Lie AKW, Yuen KY, Cheng VCC, Liang R, et al. Clinicopathological features and risk factors of clinically overt haemorrhagic cystitis complicating bone marrow transplantation. Bone Marrow Transplant 2002;29:510.

8. Runde V, Ross S, Trenschel R, Lagemann E, Basu O, Renzing-Köhler K, et al. Adenoviral infection after allogeneic stem cell transplantation: report on 130 patients from a single SCT unit involved in a prospective multicenter surveillance study. Bone Marrow Transplant 2001;28:57.

9. Hongxing Z, Granberg F, ElfineH L, Pettersson U, Svensson C. Strategic attack on host cell gene expression during adenovirus infection. J Virol 2003;77(20):11006-15.
10. García Ligero J, Mora Peris B, García García F, Navas Pastor J, Tomas Ros M, Sempere Gutierrez A y col. Cistitis hemorrágica por poliomavirus BK y JC en pacientes sometidos a trasplante de médula ósea: aspectos clínicos y manejo urológico. Actas Urológicas Españolas 2002;26(2):107.

11. Seber A, Shu XO, Defor T, Sencer S, Ramsay N. Risk factors for severe hemorrhagic cystitis following. Bone Marrow Transplant 1999;23:35.

12. La Rosa A, Champlin R, Mirza N, Gajewski J, Giralt S, Rolston K, et al. Adenovirus infections in adult recipients of blood and marrow transplants. Clin Infect Dis 2001;32:874.

13. Chen FE, Liang RSH, Lo JY, Yuen KY, Chan TK, Peiris M. Treatment of adenovirus-associated haemorrhagic cystitis with ganciclovir. Bone Marrow Transplant 1997;20:998.

14. Bonard E, Paccaud M. Abdominal adenovirosis and appendicitis. Helvet Med Acta 1966;33:164-71.

15. Feigin R, Cherry J. Pediatric Infectious Diseases. 4ta Ed. Philadelphia: Saunders Co ;1998. p. 1675.

16. US Enviromental Protection Agency EPA. [en línea] Toxicological review of Acrolein May 2003 Washinton DC. http://www.epa.gov/iris [Consulta: 03 diciembre 2003].

17. Miyamura K, Hamaguchi M, Tagi H, Kanie T, Kohno A, Tanimoto M, et al. Successful rivavirin therapy for severe adenovirus hemorrhagic cystitis after allogeneic marrow transplant from close HLA donors rather than distant donors. Bone Marrow Transplant 2000;25:54.

18. Muñoz F, Piedra P, Demunler G. Disseminated adenovirus disease in immunocompromised and immunocompetent children. Clin Infect Dis 1998;27:1196.

19. Echevarría M, Herrera F, Solimano J, Villamea L, Riera $\mathrm{L}$, de Klerk EP, et al. Cyclic recovery of adenovirus in a stem cell transplant recipient: an inverse association with graft-versus-host disease. Bone Marrow Transplant 2003;31(4):301-3.

20. Flomenberg P, Babbit J, Drobysky W, Ash R, Carrigan D, Sedmak $\mathrm{G}$, et al. Increasing incidence of adenovirus disease in bone marrow transplant recipients. J Infect Dis 1994;169:779.

21. Walls T, Shankar AG, Shingadia D. Review. Adenovirus: an increasingly important pathogen in paediatric bone marrow transplant patients. The Lancet Infect Dis 2003;3:7984. 